\title{
Full-scale fire testing and numerical modelling of the transient thermo-mechanical behaviour of steel-stud gypsum board partition walls
}

${ }^{a}$ Ayman Y. Nassif a Isamu Yoshitake ${ }^{b}$, Ahmed Allam ${ }^{\mathrm{c}}$

a School of Civil Engineering and Surveying, University of Portsmouth, Portsmouth PO1 3AH, United Kingdom. Tel: +44(0)2392842392, Fax: +44(0)2392842521 E-mail address:

ayman.nassif@port.ac.uk

${ }^{b}$ Department of Civil and Environmental Engineering, Yamaguchi University, Tokiwadai 2-16-1, Ube, Yamaguchi 755-8611, Japan

${ }^{c}$ Kingfell Fire Engineering and Risk Management Specialist, Kingfell Fire Engineering and Risk Management Specialist, Capital Tower 91 Waterloo Road London SE1 8RT, United Kingdom., Mobile: $+\underline{+44(0) 7539259519}$ | Telephone: $\underline{+44(0) 2030580185 .}$. 
Dr Ayman Nassif

Principal Lecturer in Structural Engineering

$\mathrm{t}($ direct): $\quad+44(0) 2392842392$

University of Portsmouth

School of Civil Engineering and Surveying

Portland Building

Portland Street

Portsmouth PO1 3AH

United Kingdom

Dr. Isamu Yoshitake

Department of Civil and Environmental Engineering

Yamaguchi University

Tokiwadai 2-16-1, Ube, Yamaguchi 755-8611

Japan

yositake@yamaguchi-u.ac.jp

Dr Ahmed Allam

Director

Kingfell Fire Engineering and Risk Management Specialist

Capital Tower 91 Waterloo Road London SE1 8RT

Mobile: $\underline{+44(0) 7539259519}$ | Telephone: $+\underline{+44(0) 2030580185}$

a.allam@fire-engineering.co.uk 


\section{ABSTRACT:}

In this paper, the authors present experimental observations and results of full scale standard fire tests as well as thermo-mechanical sequentially coupled finite element simulations on partition walls. A procedure for carrying out numerical simulation of the coupled-thermo-mechanical behaviour is proposed. The numerical models presented for predicting behaviour during fires were calibrated and verified by full scale fire testing. The test wall was constructed using steel C-section studs with gypsum boards fixed on both sides. The wall cavity was filled with Rockwool insulation. The partition wall was tested during exposure to the standard fire test. The thermo-mechanical behaviour of the wall was found to be heavily coupled and influenced by the physical and chemical changes in all constituents of the wall during exposure to fire.

The sequentially coupled mechanical response simulation included geometric and material non-linearity as a function of temperature. In spite of the complexity of the fire effects and the strongly coupled thermomechanical behaviour, the results of the computational model practically agree with the full scale experimental results. The numerical prediction of the maximum thermal bowing of the wall was found to be very similar to the maximum values measured during the fire test. This has practical implications for assessing the integrity such wall assemblies during exposure to elevated temperatures. The proposed procedure can be used by fire structural engineers and fire testing laboratories as a tool to assist technical assessment exercises. In addition, the proposed procedure can be used during the developmental and modification stages of building components to optimise performance during fire.

Keywords: Fire Engineering, Light Partition Walls, Fire Resistance Certification, Thermo-Mechanical Analysis 


\section{Introduction}

During the last two decades, the discipline of structural fire engineering has significantly developed adopting a new philosophy of performance-based and risk-based design. Fire resistance rating of building components is based on standard fire testing to determine the duration of exposure to fire until a failure criterion is reached. The integrity and insulation criteria for fire resistance are indeed as important for safety, if not more so, as the load-bearing criterion. How a structure behaves in a given fire scenario can be investigated using numerical models capable of coupling the thermal behaviour with the mechanical behaviour. The numerical thermal model determines the transient thermal profile in the system during exposure to a design fire scenario. The transient thermal profile is then coupled to the mechanical model to predict the transient mechanical behaviour during fire exposure. Such numerical simulations are made complex due to the non-linearity of material properties at elevated temperatures as well as changes in the geometry as a result of the thermal deformations. In addition, the changes in the boundary conditions and the degree of composite action between the constituents of the wall at elevated temperatures significantly influence the thermo-mechanical behaviour and the fire resistance rating of such systems. A number of studies related to the thermal response of such partition walls systems were conducted. However, the mechanical response during fires was not sufficiently investigated for a typical wall height of $3 \mathrm{~m}$.

Fire structural engineering is concerned with the total problem of initiation and spread of fire, the heat transfer to the structure as well as the structural system response to the fire. A number of researchers and organisations across the world have been investigating these issues with added urgency since the attacks on the World Trade Centre in 2001 which resulted in a fire design failure [26]. There are three fire resistance criteria for fire design, namely: integrity, insulation and load-bearing. The integrity failure which results in flame and/or smoke leakage from the fire compartment can result in significant loss of life as was exemplified by a fire in a residential block of flats in London [1]. 
Light non-load-bearing partition wall systems used in residential and commercial properties are required to provide a certified insulation and integrity fire resistance rating. In Europe, certification for fire resistance rating involves subjecting such walls to a standard fire according to the standard fire curve ISO834 as given in BS EN1991-1-2. Fire testing requirements for structural assemblies is mandatory in many countries for certification and fire classification purposes. BS EN 1363-1 [2] provides an outline of the fire resistance requirements and definition of fire resistance criteria. For non-load-bearing partition walls, the fire rating is determined as the duration of exposure to the standard fire until either the integrity or the insulation criterion is reached. Product manufacturers must obtain such certification before they market their systems. The certification process is quite costly and could involve repeated attempts to achieve the required fire rating with additional cost and loss of time. Accredited fire testing facilities are very limited, one or two per country. Therefore it is of huge value to develop numerical tools to be used during products development and modification in preparation for full-scale fire certification testing. Such tools can be used to predict the coupled thermo-mechanical behaviour of such systems. In addition, the performance-based and risk-based structural fire engineering design philosophy can also be made more reliable by using such numerical simulation tools and procedures.

Alfawakhiri et al. [3] provided a detailed review of the fire resistance aspects of load-bearing steel-studs walls protected by gypsum boards. The need to adopt a performance based fire engineering design was highlighted. The prescriptive design based on costly time consuming certification obtained by full-scale standard fire testing was highlighted as limiting. The criticism related to the narrow application of the standard fire testing was explored. The one-dimensional thermal model reported by Sultan [4] at the Institute for Research in Construction (IRC), National Research Council of Canada, was promising in the attempt to predict the thermal profile of such walls. Alfawakhiri et al. [3] highlighted the dearth in experimental data from fullscale fire testing which hindered the verification and calibration of numerical models. It was recommended that full-scale fire testing of such assemblies should include detailed measurements of both the thermal and the structural behaviour. The authors of this paper aimed to obtain and present qualitative and quantitative experimental data obtained from full scale fire testing on such assemblies. Sultan and Kodur [5] reported an 
experimental investigation involving light-weight partition walls constructed using either wood studs or steel studs. A number of important parameters related to such assemblies were experimentally investigated. One important conclusion was related to the effect of the presence and manner of installing insulation within the cavity of non-load bearing walls on the measured fire resistance of such assembly.

The thermal behaviour of gypsum-faced steel-stud panels were investigated by Feng et al. [6] . The panels were square $300 \times 300 \mathrm{~mm}$ in size representing a small section of a steel-stud gypsum-faced wall. The results of eight fire tests were used to calibrate and verify a numerical model for thermal analysis. The predicted temperatures and calculated temperatures seemed to provide reasonable agreement in some locations but also significant differences at others. It is noteworthy that the research effort presented by Feng et al. [6] focused only on the thermal behaviour issues. Feng and Wang [7] carried out experimental study on thin-walled structural panels. The panels were of $2.2 \times 2 \mathrm{~m}$ and loaded by a fraction of the ultimate load at ambient temperature. The thermal behaviour was established and the failure mode was noted. Failure as expected occurred as global buckling around the major axis of the stud C-sections. Local buckling in the C-section web was also observed around service opening in the studs. The effect of the stud-thickness on the fire resistance was investigated. It appears that studs with thickness less than $1.2 \mathrm{~mm}$ thick, had poor fire performance. The experimental data collected for panels $2.2 \times 2 \mathrm{~m}$ regarding the thermal behaviour together with the thermal bowing behaviour were presented.

Feng and Wang [8] presented analysis calculations for the axially loaded $2.2 \times 2 \mathrm{~m}$ panels which were tested under transient fire conditions and reported in their paper [7]. The analysis focused on comparison with the calculations presented by the ENV 1993 code of practice for designing steel buildings in Europe at that time. The effect of shifting of the neutral axis of steel sections during fire situations was investigated. Their work included mid-height deflection measurements during the fire test of the $2 \mathrm{~m}$ high panels. The estimated pure thermal bowing was compared to the measured thermal bowing taking into consideration the additional thermal bowing due to axial compression. In this paper, the authors reports significant experimental direct measurements of the pure thermal bowing of typical $3 \mathrm{~m}$ high light non-load bearing partition walls. A 
simplified numerical procedure is presented to conservatively predict the pure thermal bowing of partition walls during fire scenarios.

Mahendran and Ranawaka [9] investigated the distortional buckling behaviour of cold-formed steel columns subjected to high temperatures up to $800^{\circ} \mathrm{C}$. The investigation involved both experimental data as well as numerical simulation. The mechanical properties of the steel $\mathrm{C}$-sections were determined at steady state elevated temperatures in the range $100-800^{\circ} \mathrm{C}$. Their paper included establishing relationship between temperatures and reduction of the mechanical properties, both yield stress and Young's modulus. The investigation involved short steel studs $190 \times 290 \mathrm{~mm}$. The studs were heated and the failure load as well as the axial shortening was determined at various temperatures. Finite element modelling of the studs' behaviour was carried out adopting shell elements S4 in ABAQUS solver software. The distortional buckling behaviour of the cold-formed light gauge steel columns was determined and the results informed the local code of practice in Australia.

Chen and Young [10] established the mechanical properties for cold-formed steel at elevated temperatures both the steady state and the transient behaviour. They introduced formulation for the mechanical properties of cold formed steel material constitutive models at elevated temperatures. Such models were based on established models for stainless steel. The experimental results for the reduction factors for the mechanical properties were compared to the values established by the Australian, British and European code. It was concluded that the codes are conservative in the case of steady state but less conservative in the case of transient state.

Wakili et al. [11] investigated the thermal behaviour of small panels of gypsum boards, $1.25 \times 1.05 \mathrm{~m}$ arranged in two layers $12 \mathrm{~mm}$ each. The panels were subjected to a standard fire and the temperature profile was determined throughout the thickness. The one dimensional heat flow was numerically modelled using thermal material properties established for their study. The numerical prediction seems to be in good agreement with the measured thermal profile. 
Benichou and Sultan [12] presented the results of a large number of full-scale fire testing of light-wall and floor assemblies at the National Research Council of Canada. The numerical model for wood-studs walls provided good agreement between the measured and calculated fire performance.

Manzello et al. [13] presented data concerned with the consistency of a number of fire certification laboratories in USA, Canada and Japan. The fire test was repeated on full scale gypsum-faced steel-stud nonload-bearing partition walls. The fire rating of such walls, which was mainly based on the insulation criterion, was compared and found to be similar. There has been significant effort in modelling the thermal behaviour of gypsum-faced wood-stud walls in Canada $[14,4]$ and also in Australia where there has been significant effort in carrying out both thermal and mechanical modelling of wood-studs gypsum-faced partition wall systems [15]. They outlined a detailed numerical procedure for predicting the thermo-mechanical behaviour of light-timber framed partition walls. It is noteworthy that the thermal bowing behaviour of timber-framed walls is fundamentally different from the steel-framed partition walls. Young and Clancy [15] came to the conclusion that the gypsum board on the fire-side did not contribute to the stiffness of the wall during the fire exposure and was not included in their mechanical model. However, the gypsum board on the cold-side was included in their thermal and mechanical model. The aim was to capture the additional tensile stiffness of the composite action provided by the gypsum layer on the cold-side as the wall bows away from the fire. It is noteworthy that the stiffness of gypsum degraded rapidly after exposure to $100^{\circ} \mathrm{C}$ reaching zero at exposure to $150^{\circ} \mathrm{C}$. The rapid loss of stiffness is caused by calcinations to the hemihydrates. The stiffness of gypsum is negligible when compared to steel at ambient environmental conditions. The elastic modulus of gypsum before any effect of fire was determined as $480 \mathrm{MPa}$, i.e. $0.2 \%$ of the value for structural steel.

Although a number of attempts were made at modelling the thermal behaviour of small representative gypsum-faced steel-studs panels subjected to fire, research efforts investigating the coupled thermo-mechanical behaviour of gypsum-faced steel-studs wall systems were very limited. The mechanical response to fire exposure and the thermal bowing play a major role in the loss of integrity. The paper presents a new verified and calibrated methodology to be used in predicting the thermo-mechanical deflections of such partition wall system in a fire scenario. 


\section{Construction of the test wall}

The tested wall was a typical steel-studs gypsum-faced wall built and fire-tested according to BS EN13631:1999 [2] to determine the transient thermal and mechanical behaviour during a standard fire test. The $3000 \mathrm{x}$ $3000 \mathrm{~mm}$ wall was constructed within the opening of a concrete frame as shown in Fig.1. U-tracks measuring $75 \times 40 \times 0.6 \mathrm{~mm}$ made of galvanised steel were fixed to the top and the bottom of the opening of the concrete frame using screws at $1000 \mathrm{~mm}$ spacing.
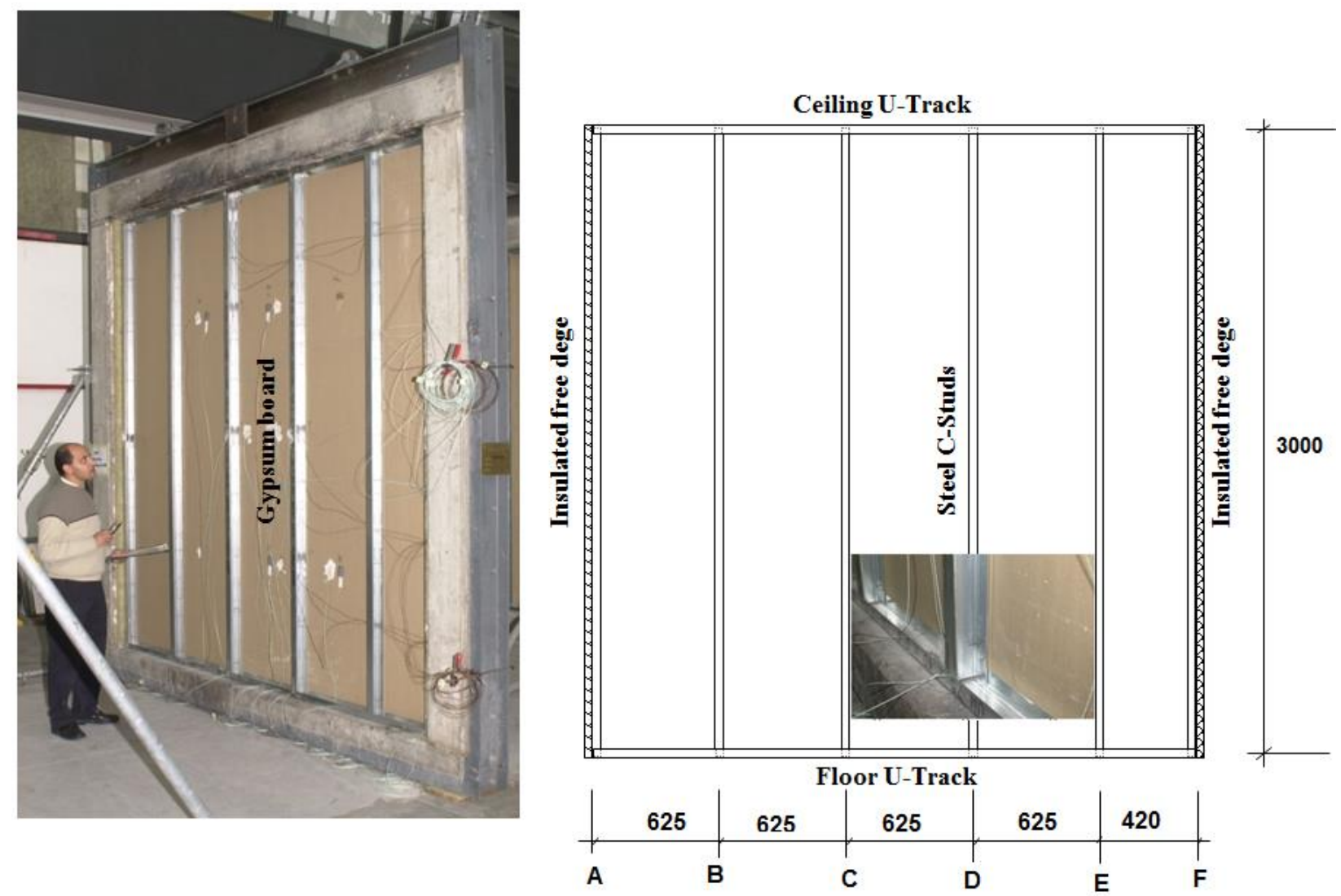

Fig. 1. Test wall under construction.

The wall incorporated six vertical galvanised steel studs measuring $75 \times 50 \times 0.6 \mathrm{~mm}$, indicated by the letters A-F in Fig.1 and Fig.2, at a spacing of $625 \mathrm{~mm}$ with one end spacing of $420 \mathrm{~mm}$. The vertical steel studs were inserted in top and bottom U-tracks and housed in place initially by friction. There was a gap 
between the bottom of the stud and the floor U-track of an average value of approximately $5 \mathrm{~mm}$. Two layers of gypsum boards (DIN 18180-GKB, EN520 Type $9.1 \mathrm{~kg} / \mathrm{m}^{2}$ ) measuring 12.5 x 1250 x $3000 \mathrm{~mm}$ each were installed on each side of the steel studs. The first layer had two joints over studs C and E (Fig.1) while the second layer had two joints over studs D and B. Where there was a joint between two boards at a stud location, one line of screws was used to fix each board to the stud. The joints in the two layers of gypsum were staggered so that the joints were not on the same steel stud. Each layer of gypsum boards was fixed to the studs using screws $3.5 \times 35 \mathrm{~mm}$ at a spacing of $300 \mathrm{~mm}$ along the height of each stud. The gypsum boards were also fixed to the top and bottom U-tracks using the same screws applying spacing of $300,600,600,600,600,300 \mathrm{~mm}$ from edge to edge. It is noteworthy that the fixing of the gypsum layers to the top and bottom U-tracks ensured that the vertical studs were not screwed to the top and bottom U-tracks. Rockwool insulation of Knauf type, 40 mm thick each, were installed into the cavity. The density of the Rockwool was $42 \mathrm{~kg} / \mathrm{m}^{3}$. Both vertical edges of the wall were insulated with the same Rockwool material between the wall and the concrete frame. Therefore the wall was free to deflect perpendicular to the plane of the wall at the vertical edges.

Thermal deformation of the wall resulted from the development thermal-gradient leading to strain-gradient across the thickness of the wall. The curvature of the wall towards the fire-side under the transient thermal exposure is referred to in this paper as thermal bowing. Fig.2 shows the general geometry of such partition wall system together with the locations of the type-k thermocouples for temperature measurements (T1 to T70) as well as locations for thermal bowing displacements perpendicular to the plane of the wall (V1 to V18). 


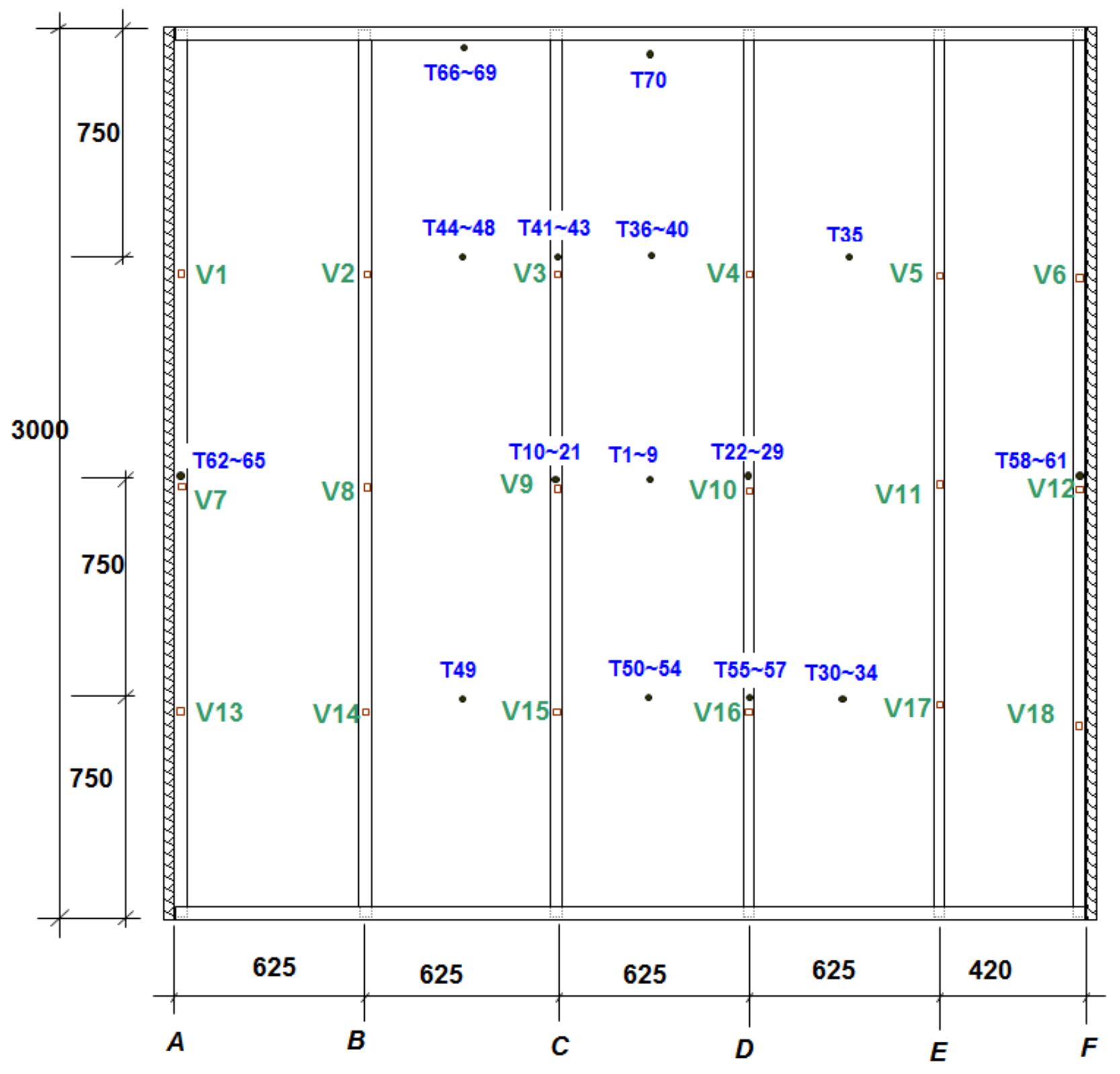

Fig. 2. Deflection and temperature measurement points on the elevation of the test wall 


\section{The standard fire test}

The test wall was constructed within a concrete frame. The wall, within the frame, was then moved to form the front side of a furnace capable of producing a fire with the time-temperature curve according to the standard fire curve given by Eq.(1) according to BS EN 1991-1-2 [16]. Fig.3 shows the wall during the standard fire test as photographed from the unexposed side. Fig.4 shows the wall positioned in place during the standard fire test after 60 minutes into the test.

$$
\theta_{g}=20+345 \log _{10}(8 t+1)
$$

Temperature $(\Theta g)$ is in ${ }^{\circ} \mathrm{C}$ and time (t) in minutes.

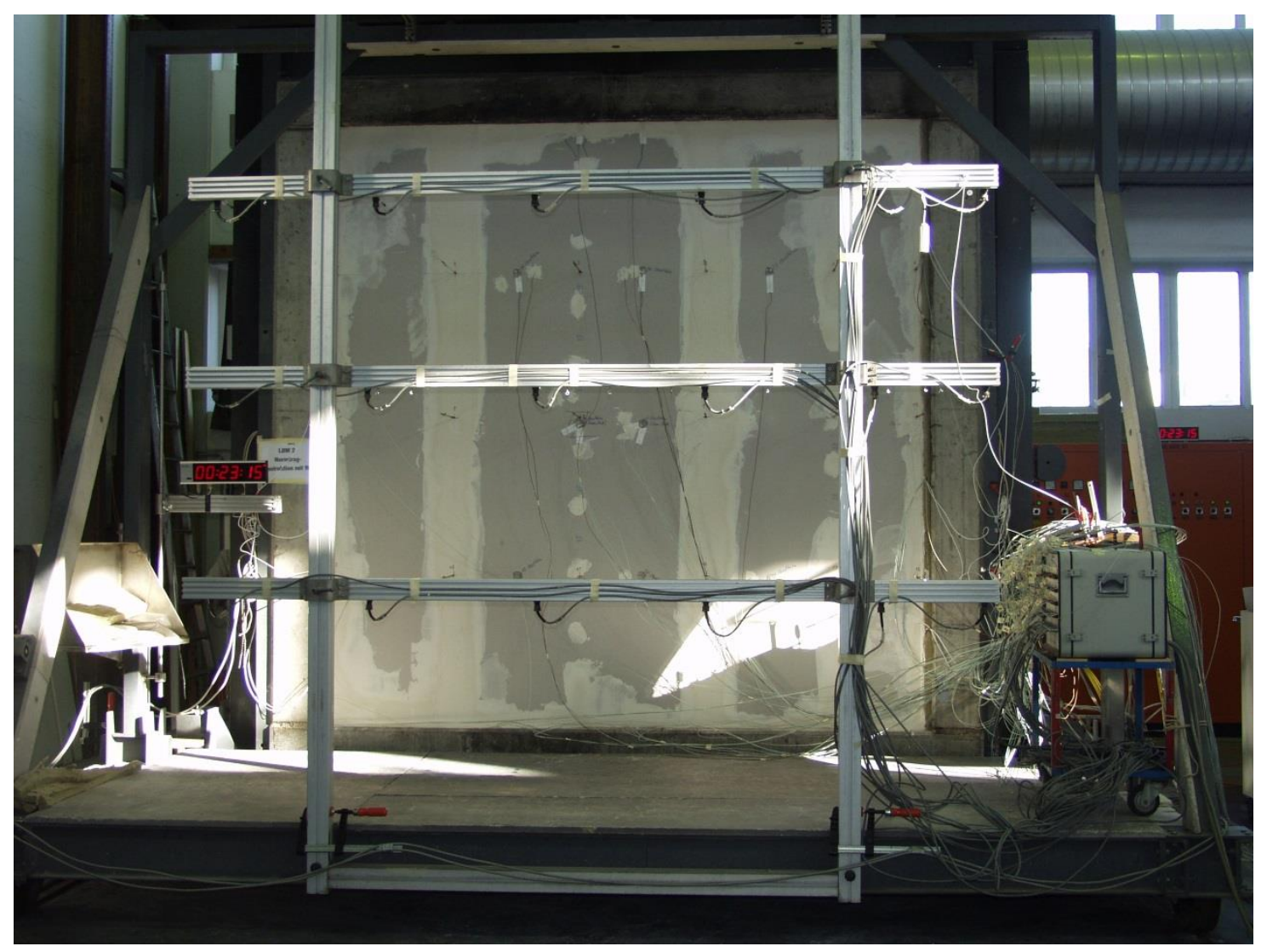

Fig.3. The standard fire test set up of the wall with the data logging arrangements. 


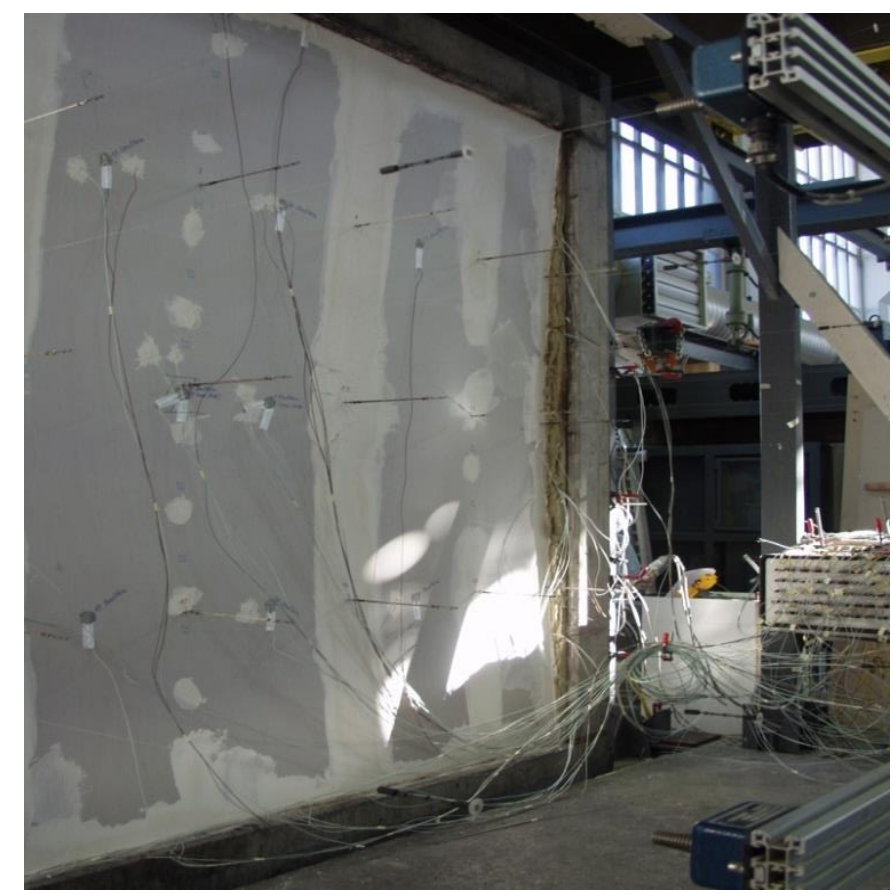

Fig.4. The test wall after bowing into the fire (one hour exposure).

The furnace temperatures were measured by standard 8 plate thermocouples placed. The readings of 8 thermocouples were used to control the gas injection. This ensured that the time-temperature curve developed adjacent to the surface of the wall was as close as possible to the standard fire curve as shown in Fig.5.

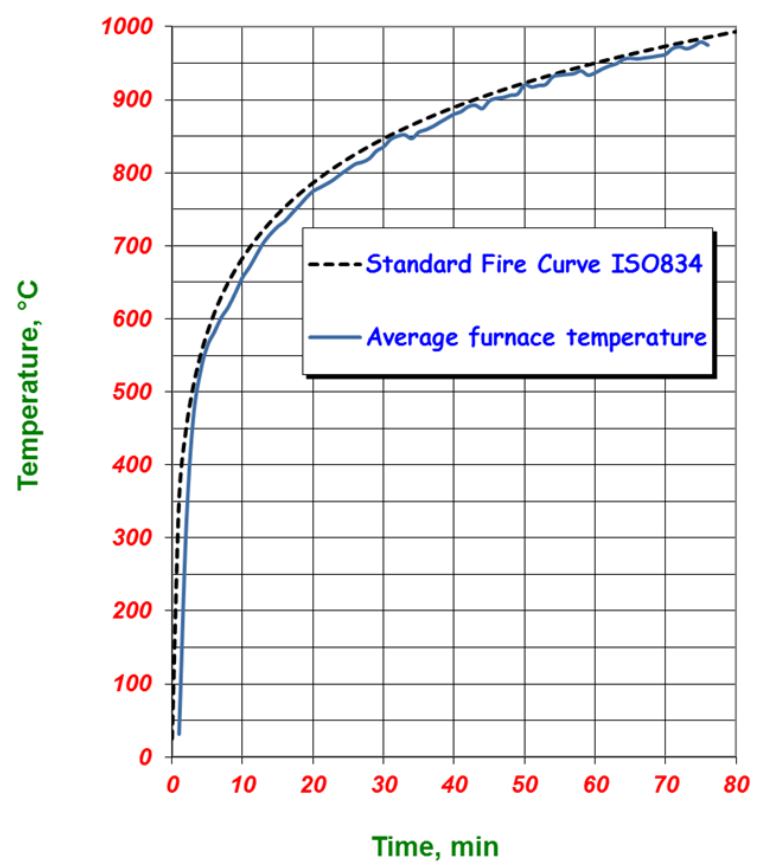

Fig.5. Standard fire curve, BS EN 1991-1-2 and furnace temperatures. 
The deformation caused by the development of a temperature gradient and variable thermal strain across the wall was monitored and recorded with reference to locations on the cold-side indicated by V1 toV18 in Fig.2. The temperature distribution across the wall was recorded using 70 thermocouples located at various locations over the plane of the wall and across the thickness as indicated in Fig. 2 by T1 to T70. The 70 thermocouples were used to establish the thermal profile at studs' locations and at mid-span between studs at various heights of the wall. The thermocouples were installed with careful arrangement for the wires to be protected during the fire test for as long as possible. The data were continuously monitored and logged throughout the fire test. In addition to the measurements of temperatures and deformation, it was decided to install a number of strain gauges along the stud to investigate issues related to the boundary conditions, in particular whether there was any degree of fixity at the top and bottom of the stud.

\section{1 Observations during the fire test}

The test wall $(3 \times 3 \mathrm{~m})$ was positioned securely at the front side of the furnace. Glass hatches at the back of the furnace allowed monitoring and recording observations regarding events on the fire-side. In addition, continuous filming and recording of significant events took place on the cold-side throughout the test. 


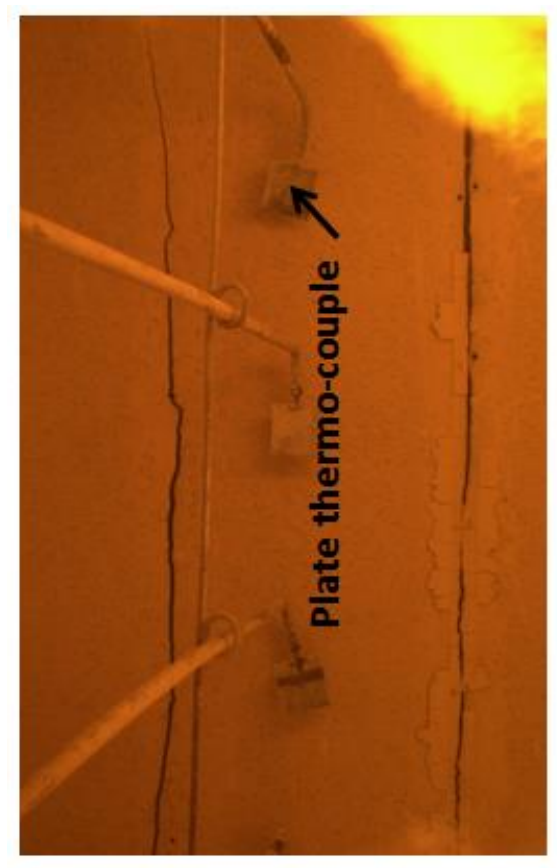

A) Cracks appearing in gypsum

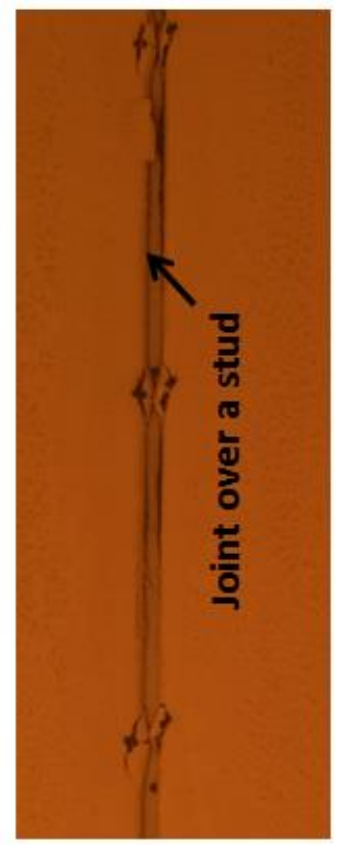

B) Loss of composite action at joints

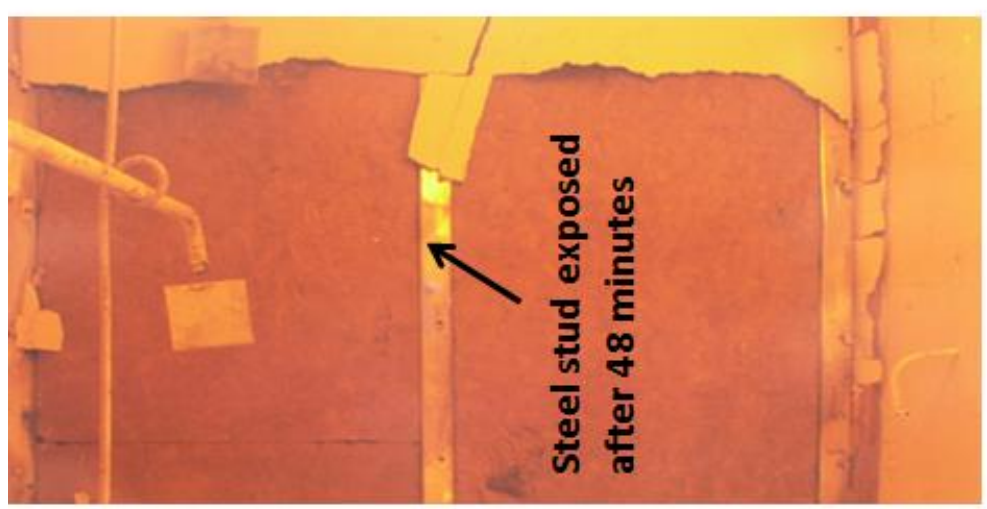

C) Total falling off sections of the gypsum boards

Fig.6. Behaviour of wall during the fire test as observed from the fire-side

On the fire-side, at about 8 minutes into the test, cracks started to appear in the gypsum boards, particularly at the screw positions along the studs, as shown in Fig.6 A). At about 25 minutes, there was obvious total separation of the first layer of gypsum from a number of screws. At about 48 minutes, sections of the gypsum boards started to fall off completely resulting in exposure of the steel studs to the fire. 
On the cold-side, at about 33 minutes, clouds of smoke and steam were visible at the top section of the wall. At 40 minutes, there was evidence of moisture and water emerging at the bottom of the wall. The water vapour is released during the dehydration process of gypsum.

After the fire test was completed, the wall was left to cool in the laboratory environment until a detailed post-fire examination took place a week later. As expected, the sections of the wall where the insulation fell off during the test suffered severe damage. However, in general the two layers of gypsum boards on the cold-side were not seriously damaged unless the insulation was dislodged during the fire test, as shown in Fig. 7.

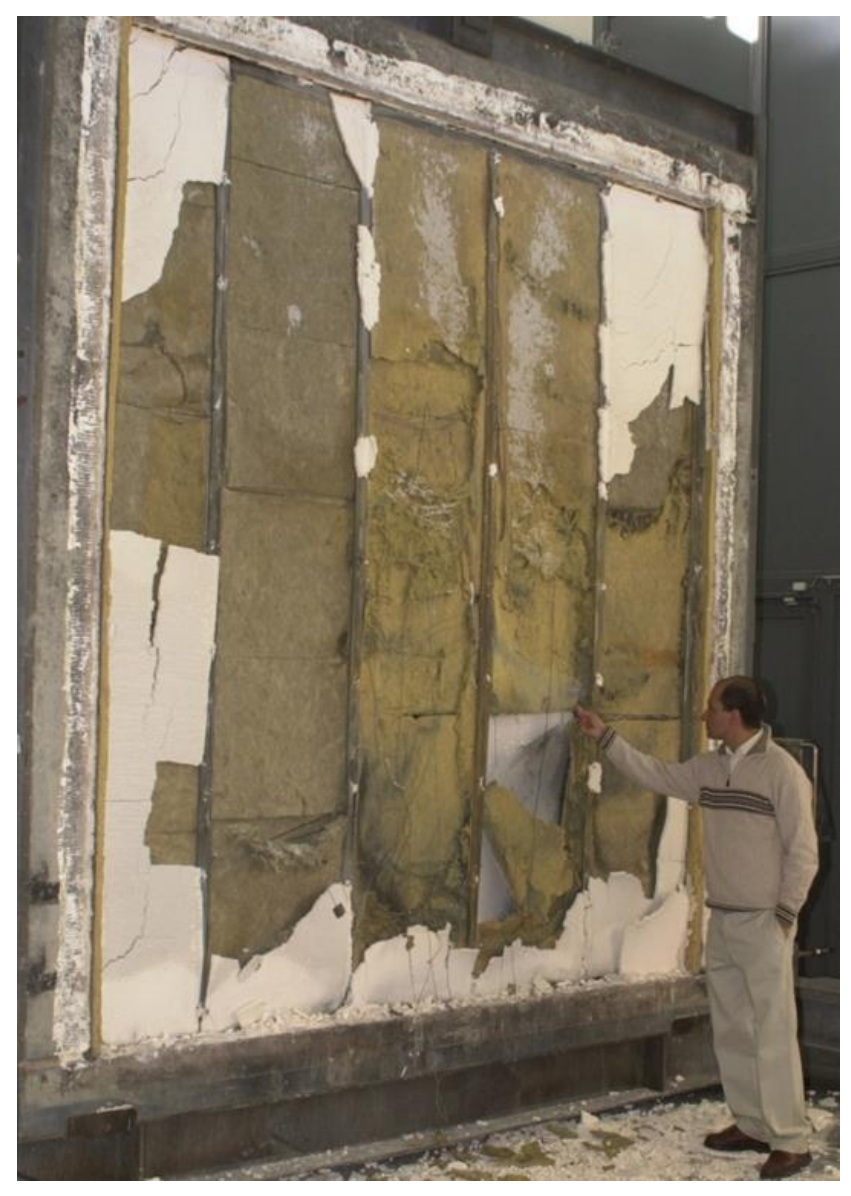

Fig.7. Post-fire examination of the test wall

The gypsum layers on the fire-side lost integrity with obvious degradation or total loss of the composite action, particularly in the vertical direction associated with thermal bowing. The gypsum boards on the coldside retained some of the stiffness and provided at least lateral support in the plane of the wall for the studs as 
well as torsional restraint for the thin flanges. This observation proved to be instrumental in the attempt to capture the coupled thermo-mechanical behaviour to predict the thermal bowing of such wall systems during exposure to fires.

Prediction of thermal bowing of non-load-bearing partition walls is linked to the integrity criterion of fire resistance which is concerned with flame and smoke leakage from the fire compartment. The ability to predict the thermo-mechanical behaviour of such systems can be used by the manufacturers to optimise the fire performance of their products ensuring that the certification and marketing of their products is cheaper and quicker. The post-fire examination of the bare steel studs, after removal of all gypsum boards and Rockwool insulation, showed very interesting patterns. The deformation of the screws and the local buckling behaviour of the flanges indicated significant loss of composite action as well as the limited contribution to the stiffness of the system from the gypsum boards. The slippage in the direction of thermal bowing was obvious. However, the restraining action in the plane of the wall was also evident.

During the visual examination of the studs, the heating pattern over the surface of the wall was highlighted by changes in roughness of the steel surface which resulted from heat damage to the protective coating. It is noteworthy that the track at the top was observed to pull off the frame. In addition, the gap between the studs and the top track was observed to increase to values of 9 to $22 \mathrm{~mm}$.

\section{Numerical modelling}

Fig.8 shows a part of wall cross-section at a stud location together with statements regarding significant issues needed for consideration in the thermal model. 


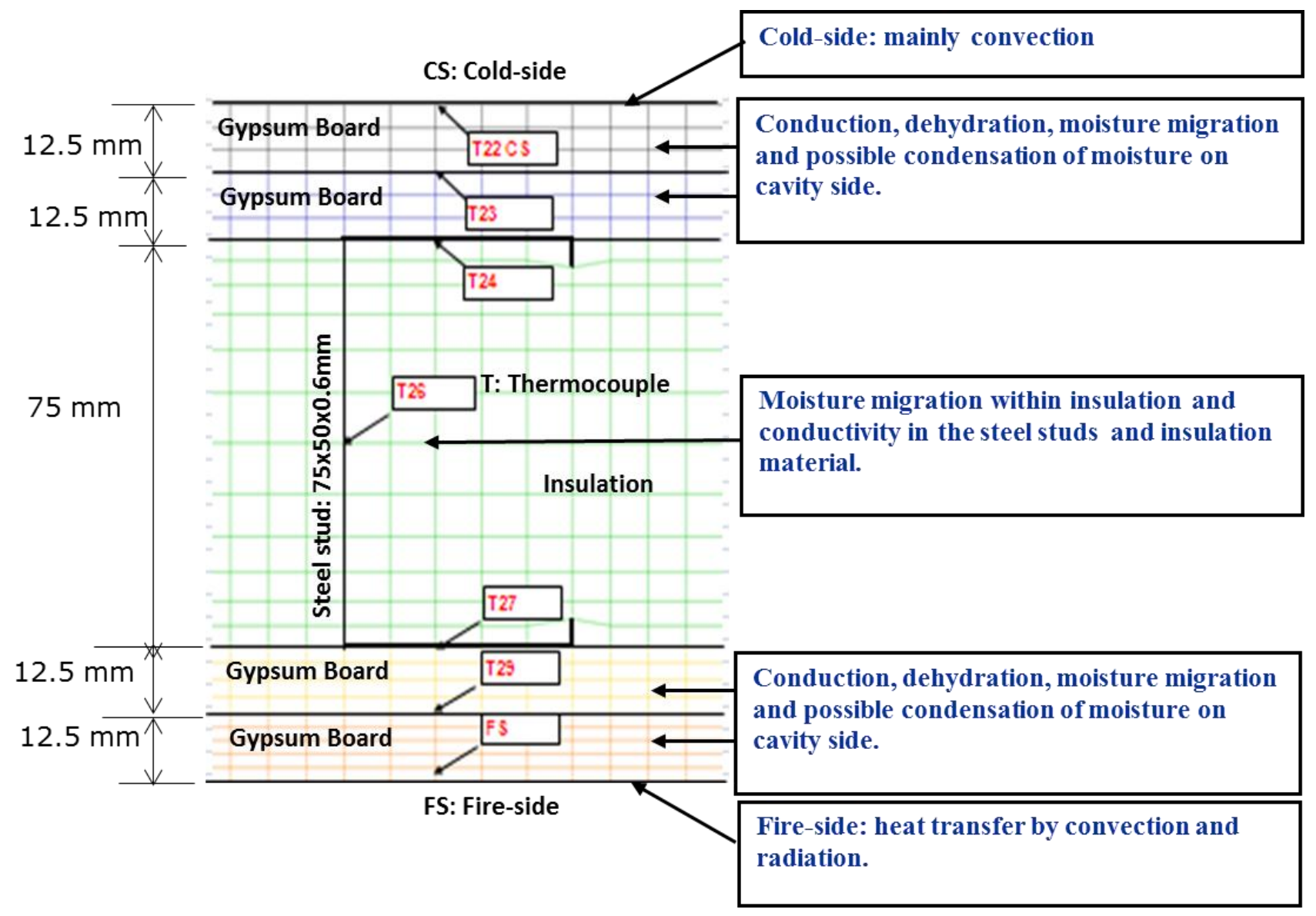

Fig.8. Cross-section of the wall at steel stud locations with indication of thermal modelling issues.

The wall was constructed by experienced construction practitioners. The construction procedure was similar to the method adopted in practice. The floor and ceiling tracks were fixed to the frame. The tracks were $75 \times 40 \times 0.6 \mathrm{~mm}$ cold-formed sections. The vertical studs $(75 \times 50 \times 0.6 \mathrm{~mm})$ were inserted between the tracks. It was an important observation that the studs were housed in the tracks by friction alone with a gap of about 5 to $11 \mathrm{~mm}$ at each end of the stud. Therefore, the studs were free to change in length vertically. This had implications in capturing the boundary conditions in the sequentially coupled thermo-mechanical analysis. The heat transfer by conduction through the wall was determined using Finite Element software, Abaqus. The thermal properties of the constituent materials were temperature dependent.

While thermal numerical modelling of such walls has been explored by various researchers $[17,4]$, there is less evidence of research into modelling the thermo-mechanical coupled behaviour of large scale $(3 \times 3 \mathrm{~m})$ 
steel-studs gypsum faced insulated partition walls. Predicting the mechanical behaviour is made complicated due to the difficulty in capturing the transient mechanical behaviour of the constituent materials, in particular gypsum boards. Aspects of cracking, falling off and degradation of the force-slippage relationship between the gypsum and the steel studs were some of the complex issues needing consideration. In addition, the sequentially coupled thermo-mechanical analysis is naturally affected by inaccuracies in the thermal model. Outlines of the issues needing consideration in the mechanical model are highlighted in Fig.9.

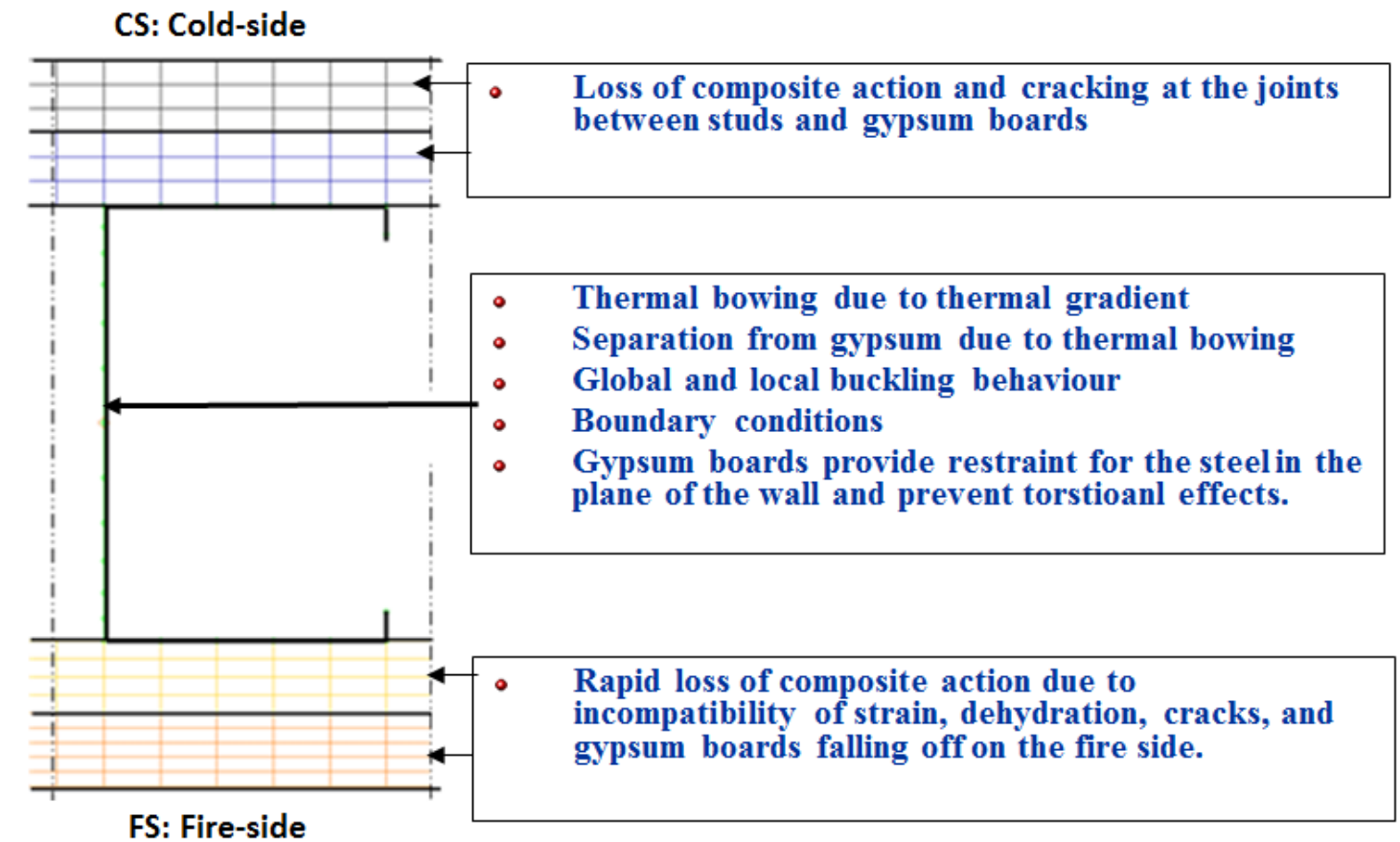

Fig.9. Considerations for the mechanical model

Based on observations of the physical behaviour during and after full scale fire tests, the author proposes a simplification for carrying out a sequentially coupled thermo-mechanical analysis on steel-studs gypsum-faced walls as indicated in Fig.10. The proposed procedure includes the dominant factors in the mechanical behaviour. First a transient thermal analysis is performed on all constituents of the wall using appropriate transient material models. The mechanical response of the wall is established by reading the temperature distribution at all time-intervals to determine the differential thermal strain distribution and the resulting thermal bowing. The authors propose that the mechanical model should not include the gypsum boards or the insulation 
material. The mechanical properties of gypsum at elevated temperatures are known to degrade quite rapidly with total loss of stiffness after exposure to $150^{\circ} \mathrm{C}$ [15]. In addition, the composite force-slippage resistance was observed to degrade in the direction of bowing. At any rate, the stiffness of gypsum is about $0.2 \%$ of the steel stiffness. Only the steel stud is therefore included in the mechanical model. The transient mechanical properties of steel at elevated temperatures were according to BS EN1993 [18].
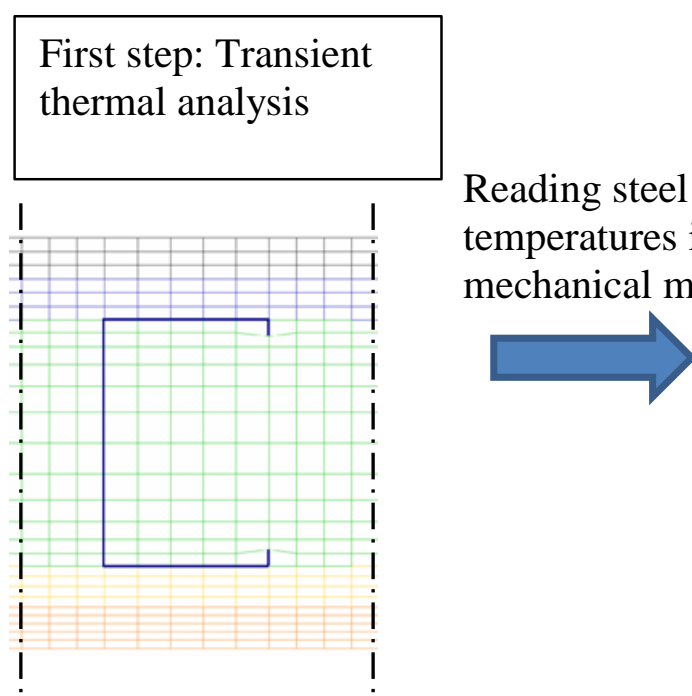
temperatures in the mechanical model

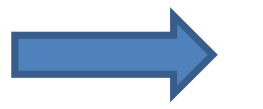

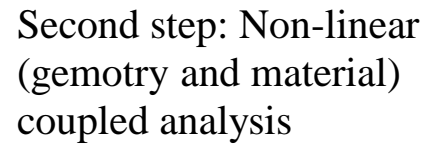

Second step: Non-linear (gemotry and material) coupled analysis

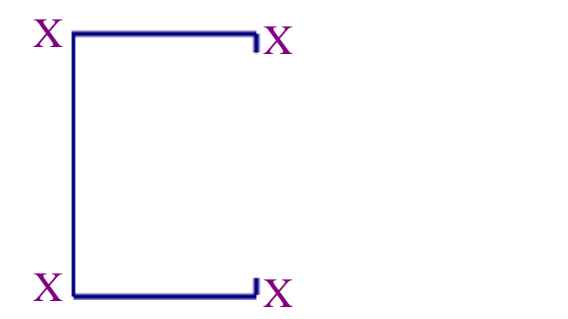

$\mathrm{X}$ : Restraint in the plane of the wall

Fig.10. Proposed methodology for sequentially coupled thermo-mechanical analysis.

However, the role played by the gypsum boards in the mechanical behaviour is captured by applying appropriate boundary conditions to the steel stud. Repeated observations of the loss of composite action between the gypsum boards and the steel stud in the vertical direction at an early stage of the fire as soon as thermal bowing and softening of the gypsum took place resulted in this idealisation. It became evident that the main role the gypsum boards play in the mechanical behaviour is to provide restraints in the plane of the wall to the stud as well as preventing the torsional effects.

\subsection{Modelling procedure}

\subsubsection{General}

Finite Element numerical modelling was carried out using Patran as pre and post processor with Abaqus solver. For the gypsum and insulation material volume finite elements were used. For the steel studs, the 
thermal analysis was carried out using volume elements and the mechanical analysis using shell elements. It is noteworthy that volume elements give much better prediction of the thermal distribution in the steel but are not appropriate for the mechanical analysis where non-linear and buckling aspects need to be considered. Hence the use of different elements for the two types of analyses. The initial modelling effort aimed at including the entire geometry of the wall in the model, as shown in Fig. 11. This was computationally extremely demanding. Therefore, it was decided to model a width of $625 \mathrm{~mm}$ of the wall including one steel stud as indicated in Fig. 12 . It is noteworthy that the numerical simulation efforts included extensive trails of various much densities and initial parametric study in relation to the various thermal and mechanical material properties available.

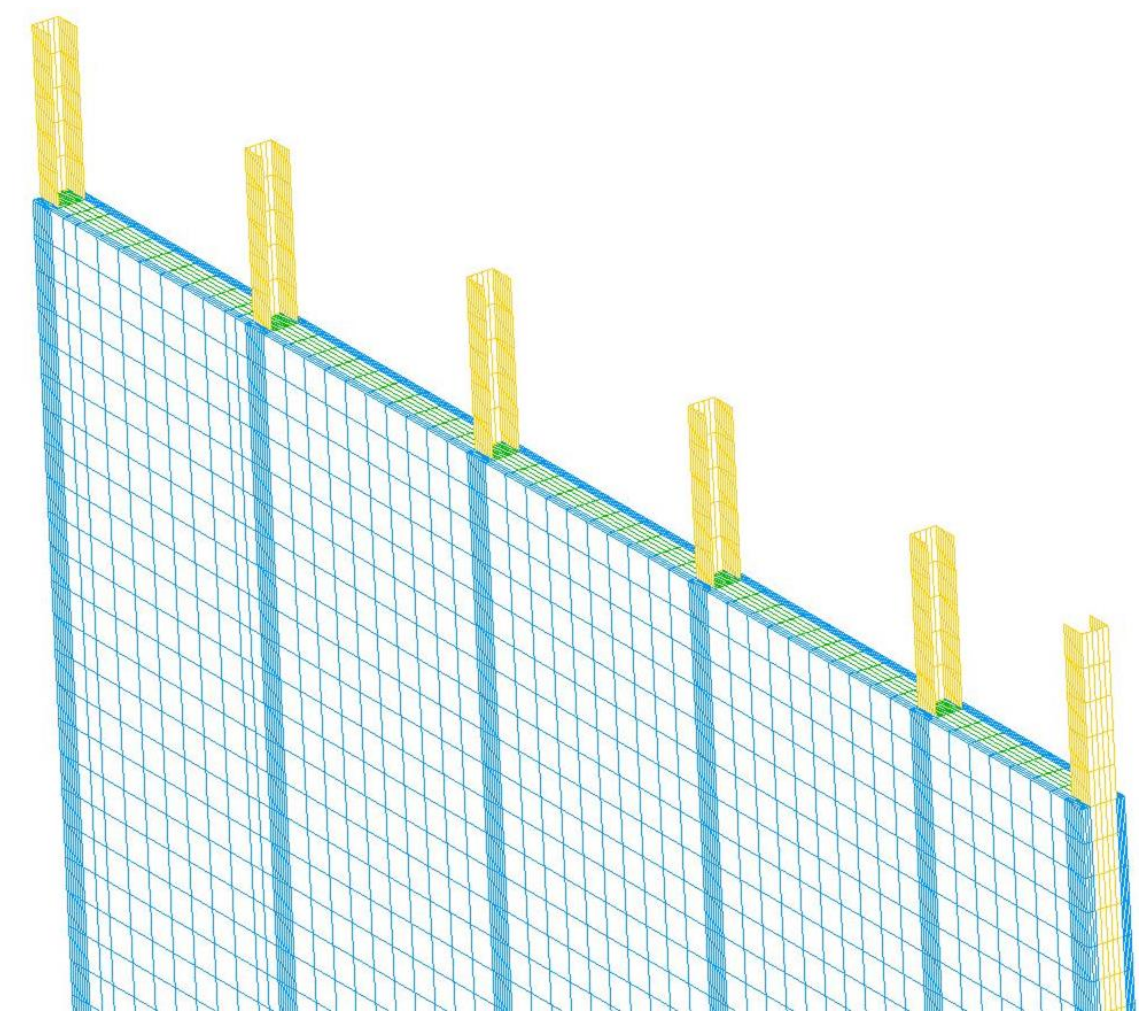

Fig.11. Initial modelling of the entire wall. 


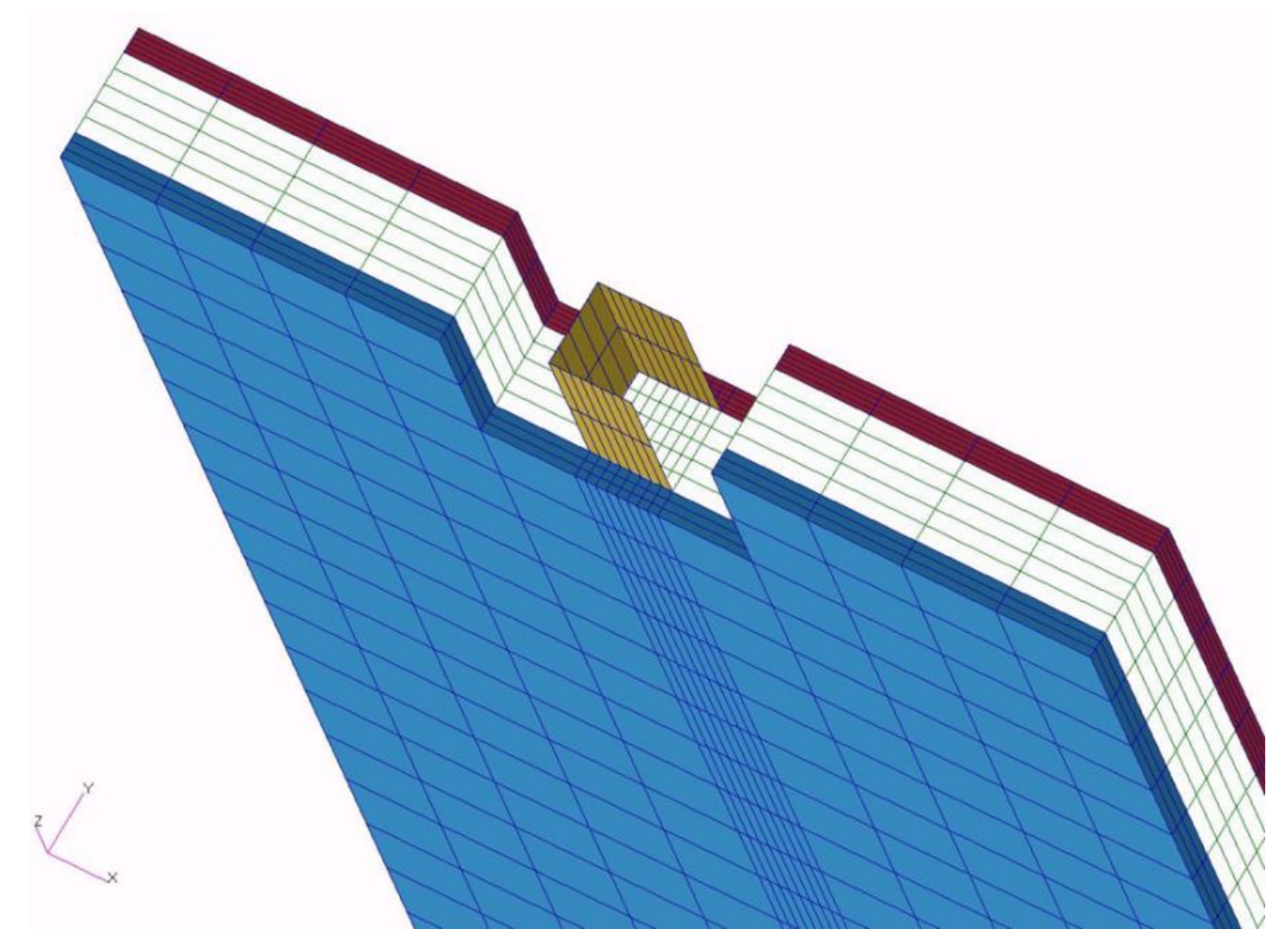

Fig.12. Section of the wall, $625 \mathrm{~mm}$ wide, used for the thermo-mechanical simulation

\subsubsection{Thermal properties:}

Specific heat of the gypsum boards as determined experimentally by Sultan [4] for X-Type board using DuPont DSC with heating rate of $2{ }^{\circ} \mathrm{C} / \mathrm{min}$. Similar values seem to have been used in simulations research in Australia [19]. Mehaffey et al. [14] reported that the energy required to dehydrate the Gypsum and vaporize the water can be taken as $625 \mathrm{~kJ} / \mathrm{kg}$ of gypsum. Thomas [20], in New Zealand, reviewed the available literature related to the thermal properties of gypsum boards at elevated temperatures. More recently, Hopkin et al. [21, 22] and Lennon et al. [23] presented significant experimental data related to the thermal behaviour of similar assemblies but with wood studs. For the sake of the research effort presented here the specific heat values were adopted as presented in Fig. 13. Various material properties according to other researchers were included in the numerical experimentation but the values presented by Sultan [4] were best suited to the nature of gypsum material used in this programme of work. It is noteworthy that the specific heat two spikes, presenting the two dehydration fronts, had to be slightly truncated to remove numerical instability in the thermal simulation. 


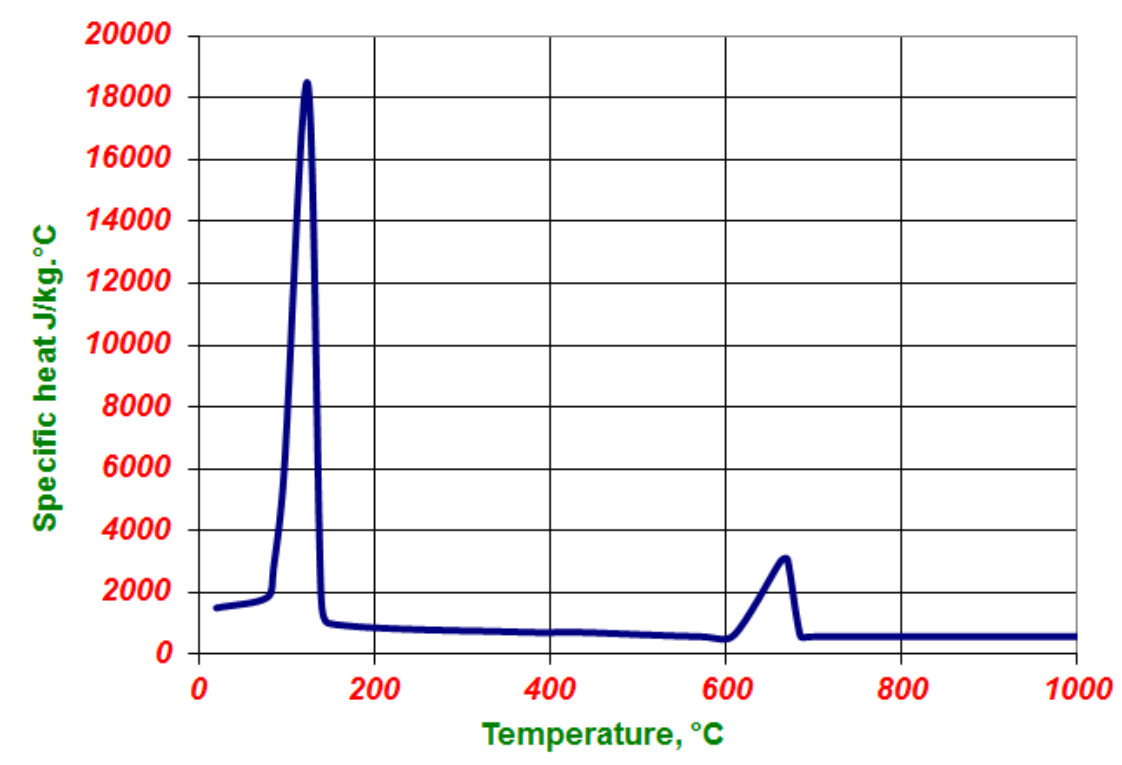

Fig.13. Specific heat of gypsum at elevated temperature [4]

The thermal model took into consideration that gypsum contains $20 \%$ by weight chemically combined water. During exposure to fire the first dehydration occurs at $120^{\circ} \mathrm{C}$ during which $450 \mathrm{~kJ} / \mathrm{kg}$ is used to release and evaporate the chemically combined water and $40 \mathrm{~kJ} / \mathrm{kg}$ to evaporate the free water. Secondary dehydration takes place at $650^{\circ} \mathrm{C}$ requiring energy consumption of $170 \mathrm{~kJ} / \mathrm{kg}$. The thermal conductivity of gypsum was taken as $0.25 \mathrm{~W} / \mathrm{m}^{\circ} \mathrm{C}$ at $20^{\circ} \mathrm{C}$ reducing to $0.12 \mathrm{~W} / \mathrm{m}^{\circ} \mathrm{C}$ between $100^{\circ} \mathrm{C}$ to $700^{\circ} \mathrm{C}$ increasing to $0.27 \mathrm{~W} / \mathrm{m}^{\circ} \mathrm{C}$ at $800^{\circ} \mathrm{C}$ and remaining constant at higher temperatures. The density of gypsum was taken as $698 \mathrm{~kg} / \mathrm{m}^{3}$ at $20^{\circ} \mathrm{C}$ reducing linearly to $576 \mathrm{~kg} / \mathrm{m}^{3}$ at $800^{\circ} \mathrm{C}$ and staying constant at higher temperatures. 
Table 1. Thermal properties

\begin{tabular}{|l|l|l|l|}
\hline & $\begin{array}{l}\text { Specific heat } \\
\mathrm{J} / \mathrm{kg}^{\circ} \mathrm{C}\end{array}$ & $\begin{array}{l}\text { Thermal conductivity } \\
\mathrm{W} / \mathrm{m}^{\circ} \mathrm{C}\end{array}$ & $\begin{array}{l}\text { Density } \\
\mathrm{kg} / \mathrm{m}^{3}\end{array}$ \\
\hline Gypsum & According to Fig.13 & $20-100^{\circ} \mathrm{C}, 0.25$ & $20^{\circ} \mathrm{C}, 698$ \\
\hline & & $100-700^{\circ} \mathrm{C}, 0.12$ & $\mathrm{~T}>=800{ }^{\circ} \mathrm{C}, 576$ \\
\hline & & $\mathrm{T}>=800,0.27$ & \\
\hline Mineral Wool & 840 & & 25 \\
\hline Steel & & 0.035 & \\
\hline & According to Fig.14 & $20{ }^{\circ} \mathrm{C}, 53.3$ & 7850 \\
\hline & & $\mathrm{T}>=800{ }^{\circ} \mathrm{C}, 27.4$ & \\
\hline
\end{tabular}

The thermal properties of steel were according to BS EN 1993 [18]. The steel specific heat used in this research is represented in Fig.13 according to the reference [18]. Again, the spike was slightly truncated to improve the numerical stability. The thermal conductivity of steel was taken such that it reduced linearly from $53.3 \mathrm{~W} / \mathrm{m}^{\circ} \mathrm{C}$ at $20{ }^{\circ} \mathrm{C}$ reaching $27.4 \mathrm{~W} / \mathrm{m}^{\circ} \mathrm{C}$ at $800{ }^{\circ} \mathrm{C}$ then remaining constant at higher temperatures. The steel density was taken as $7850 \mathrm{~kg} / \mathrm{m}^{3}$, for the entire temperature range, as shown in Table 1 .

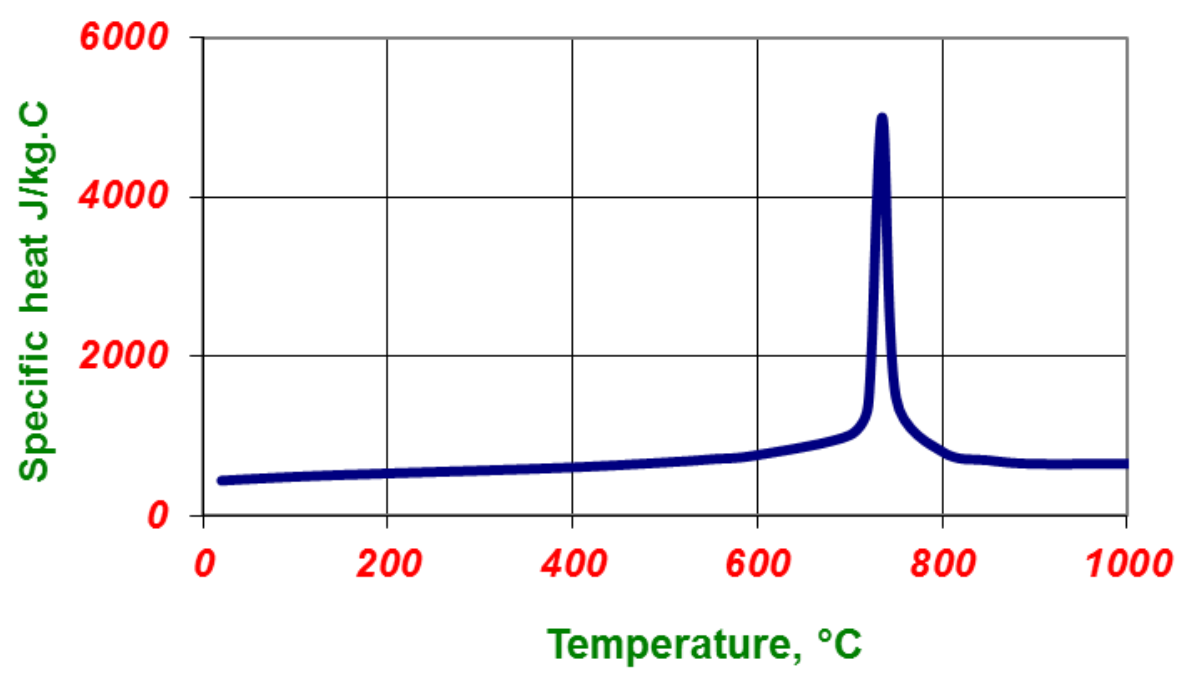

Fig.14. Specific heat for steel at elevated temperatures. BS EN 1993 
Values of the effective thermal properties of the Rockwool insulation in the wall cavity can be found in the European guidelines for fire safety in timber structures [24]. However, based on manufacturer data, the specific heat for Rockwool was taken as $840 \mathrm{~J} / \mathrm{kg}^{\circ} \mathrm{C}$ and the thermal conductivity was taken as $0.035 \mathrm{~W} / \mathrm{m}^{\circ} \mathrm{C}$. It is noteworthy that at the time the simulation for this work was carried out, the European guidelines data were not available.

The heat transfer from the furnace to the test wall using values for convection and radiation was modelled by the application of the standard fire curve as provided by BS EN 1991-1-2 [16] and presented in Fig.5 directly on the wall. The convection on the cold-side was based on a room temperature of $20^{\circ} \mathrm{C}$ and a coefficient of convection of $9 \mathrm{~W} / \mathrm{m}^{2 \circ} \mathrm{C}$ [16]. The question related to the application of the ISO timetemperature curve directly on the exposed side of the wall was considered. The experimental readings of thermo-couple, placed at the interface between the two gypsum layers (T29) on the fire side, at the point of falling of the gypsum layer exposed to the fire showed that the temperature reading reached almost equal the temperature value as given by the ISO standard fire curve, as shown in Fig.15. These temperature readings confirmed the application of the standard fire time-temperature curve directly to the exposed side in the thermal model. 

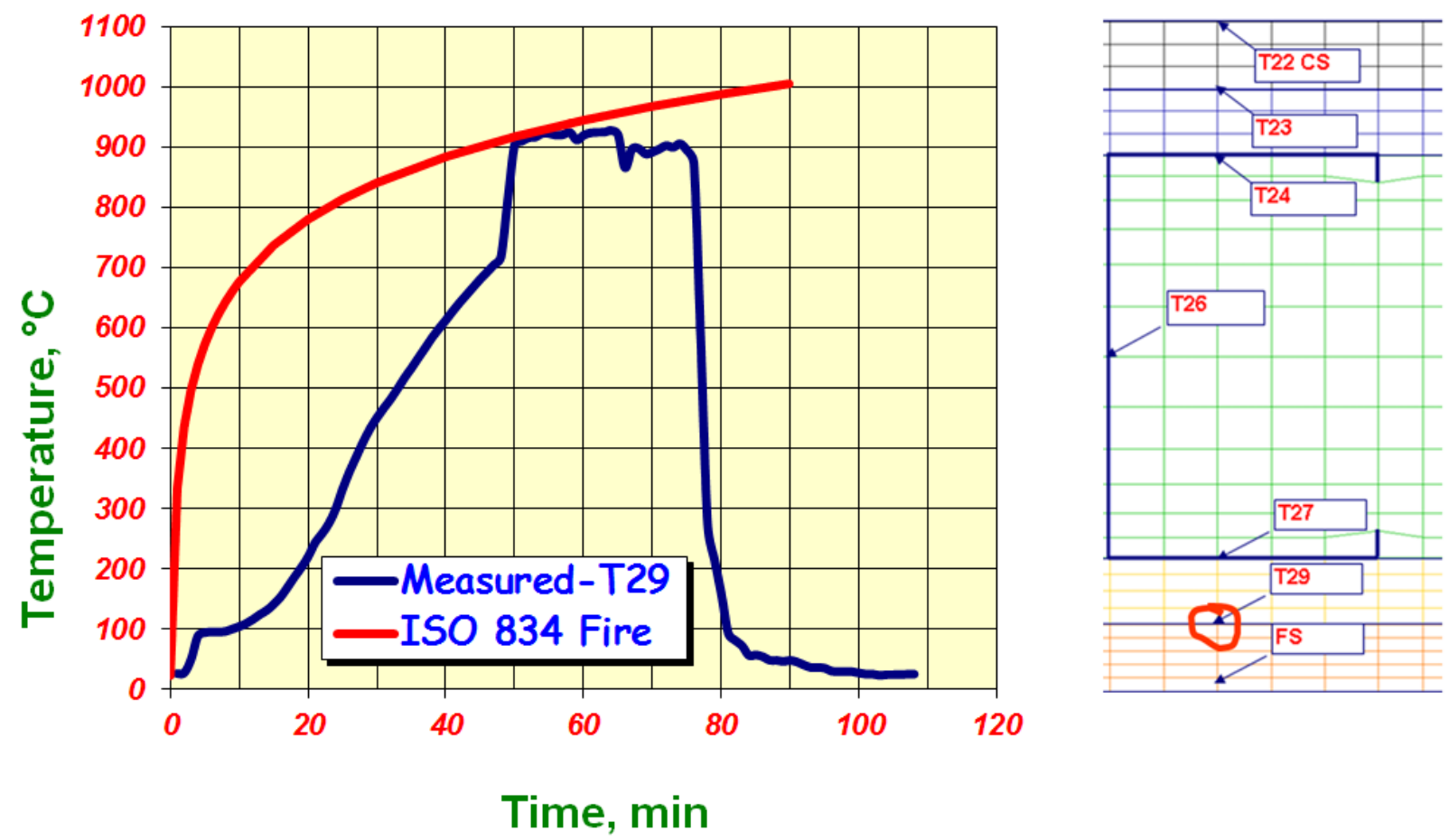

Fig.15. Temperature recorded by T29 compared to the ISO fire curve

\subsubsection{Mechanical properties}

The transient mechanical properties of steel during exposure to the fire were based on the reduction factors as provided in BS EN 1993-1-2 [18]. The material model included the elastic properties as well as the plastic properties. The reduction factors provided by Annex E BS EN 1993-1-2 [18] were used as shown in Table 2. The tensile strength for steel was based on BS EN 1993-1-3 [27].

Table 2. Reduction factors of the mechanical properties of steel, according to Class 4 Annex E BS EN 1993-1-2

\begin{tabular}{|l|l|l|}
\hline Temperature ${ }^{\circ} \mathrm{C}$ & Reduction factor for stiffness & Reduction factor for yield stress \\
\hline 20 & 1.00 & 1.00 \\
\hline 200 & 0.90 & 0.91 \\
\hline 400 & 0.70 & 0.69 \\
\hline 500 & 0.60 & 0.52 \\
\hline 600 & 0.31 & 0.34 \\
\hline 800 & 0.09 & 0.11 \\
\hline 900 & 0.06 & 0.06 \\
\hline $\mathrm{E}\left(20^{\circ} \mathrm{C}\right)=210 \mathrm{GPa} \&$ Tensile strength $\left(20^{\circ} \mathrm{C}\right)=300 \mathrm{MPa}$ \\
\hline
\end{tabular}


The sequentially coupled thermo-mechanical analysis was carried out in two steps. First the transient thermal analysis was performed. The steel temperatures were then read from the thermal results file into the mechanical analysis model at each time increment. The gypsum boards were assumed to prevent both torsional buckling and lateral buckling in the plane of the wall as shown in Fig. 10.

\section{Results and discussion}

\subsection{Thermal analysis (or simulations)}

Fig.16 shows the measured temperatures across the wall at a stud location T22 to T29 compared to the numerically predicted values determined according to the methodology described here.
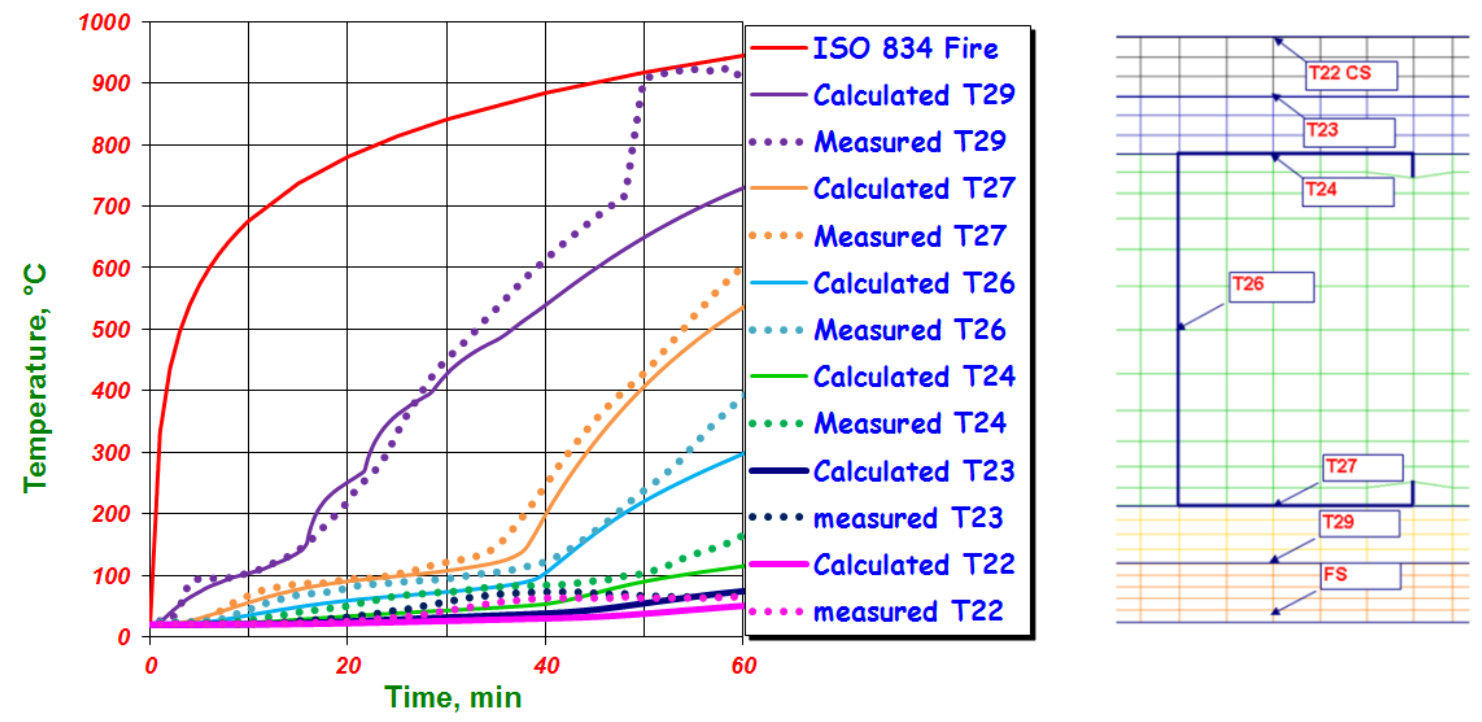

Fig.16 Measured temperatures compared to calculated values across the test wall.

There seems to be reasonable agreement between the measured thermal profile and the calculated values. The temperature recorded by T29, which was inserted at the interface between the two gypsum boards, was modelled reasonably well up to 30 minutes. This is the point at which the gypsum layer on the fire side started to suffer severe cracking leading to total falling off after 48 minutes into the test thus exposing the 
thermocouple directly to the fire. It is noteworthy that the reading taken from this location at the instant the gypsum layer fell off confirmed the value given by the standard fire curve as shown in Fig.16.

Thermocouple T27 was installed directly on the flange of the steel stud. It is very significant that the calculated temperatures and the measured values are similar.

This is an example of a good prediction of the steel temperatures. The observed divergence at about 50 minutes between the predicted and the measured values are again attributed to the falling off of the first gypsum layer on the fire-side.

It is noteworthy that the calculated thermal profiles through the steel stud were relatively better than the values calculated for the gypsum board on the unexposed side of the wall (T22 and T23). This has been the case in a number of simulations which were carried-out by the author on various geometries and sizes of similar walls. The temperatures recorded by T22 on the cold-side of the wall were generally well predicted at the initial stages of the test to about 20 minutes' exposure. However after this point, the measured values were higher than the calculated values but converging towards the end of the test.

This phenomenon is believed to be caused by energy transportation via steam movement within the wall cavity. As the maximum temperature recorded by $\mathrm{T} 22$ was $80^{\circ} \mathrm{C}$, this error in predicting the cold-side temperature is insignificant for the determination of fire resistance. The insulation criterion for fire resistance requires that the average increase of the temperature over the wall does not exceed $160^{\circ} \mathrm{C}$ and the maximum increase does not exceed $180^{\circ} \mathrm{C}$ [2]. The effect of energy transportation through steam movement seems to diminish once the dehydration of the gypsum on the fire-side is nearly complete. This diminishing effect was observed at approximately 30 minutes into a number of fire tests. Research efforts by Ang and Wang [17] to account for mass transportation proposed an equivalent value for specific heat to be used. Similar patterns of underestimation of the cold-side temperature predicted either by thermal-transfer alone or by a combined thermal-and-mass transfer models were observed. 


\subsection{Thermo-mechanical sequentially coupled analysis}

The thermal bowing of the wall was obviously expected to be dominated by the thermal profile across the steel studs. Thermal bowing occurs as a result of the development of thermal gradient across the thickness of the wall. The transient thermal gradient results in a strain gradient which in turn results in the curvature and bowing of the wall into the fire-side.

The role the gypsum boards play in the mechanical behaviour was scrutinised by carrying out detailed investigation of the crack patterns at the connection between the gypsum boards and the studs both during and after the fire. Appropriate idealisation capturing the boundary conditions realistically in the numerical mechanical model was investigated through a sensitivity analysis.

Fig.17 shows the deformation measurements indicating the maximum bowing into the fire at location V9. The sequentially coupled thermo-mechanical analysis, which was carried out according to the proposed procedure in Fig.10, showed good prediction of the maximum thermal bowing of the entire wall up to 60 minutes of exposure. At the initial stage of the fire, up to 15 minutes, the predicted values are slightly lower than the measured values of displacement. This could be attributed to the initial adjustment of the instrumentation and slackness in the system rather than a thermo-mechanical coupled behaviour. At later stages of the fire the measured maximum displacement and the calculated values are in good agreement as shown in Fig.17. 


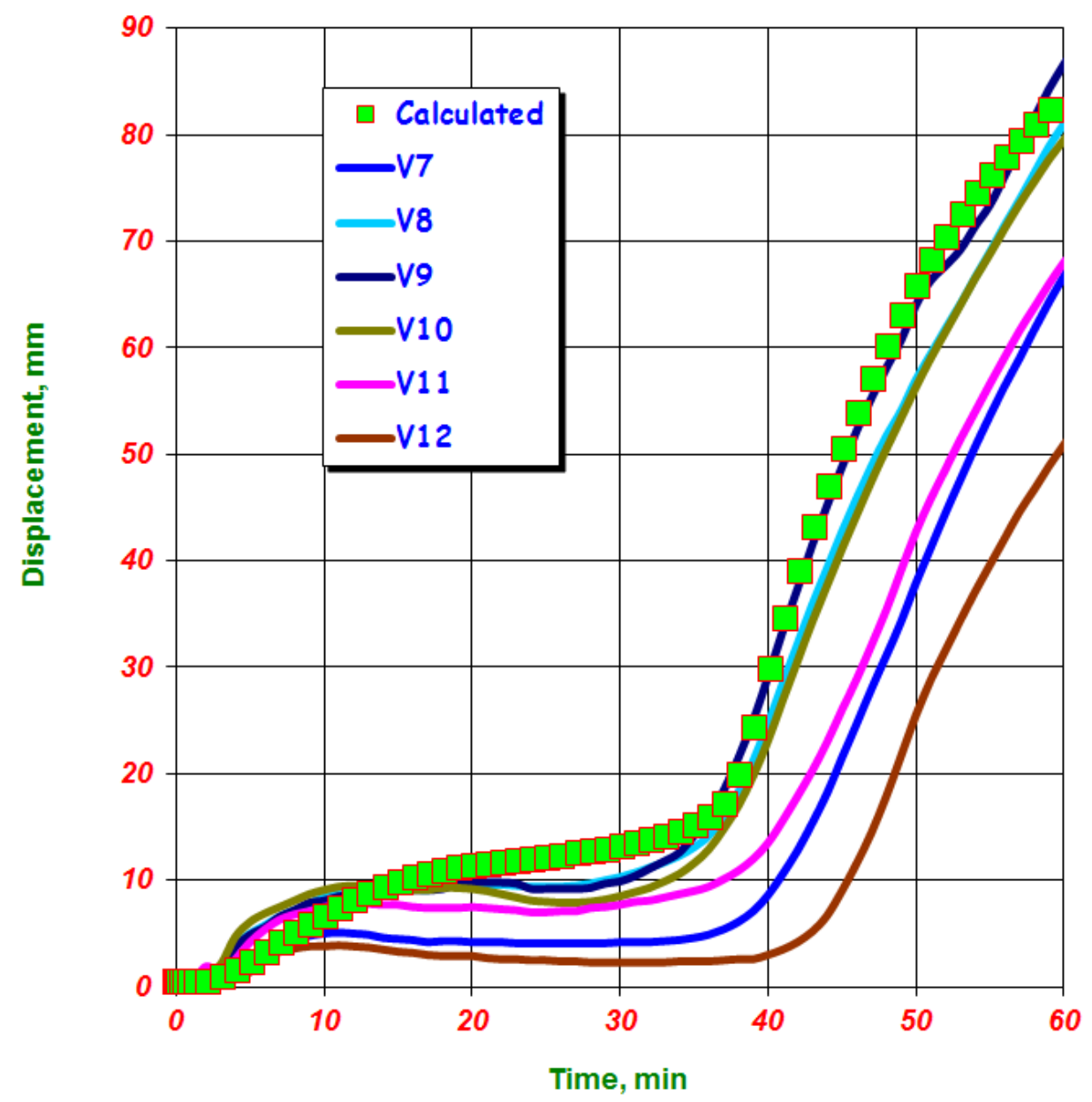

Fig.17. Measured thermal bowing compared to calculated displacement

Similar predictions of deformations on a number of wall systems were performed to verify the repeatability and applicability of this proposed procedure for commercial purposes. A good thermal model to predict reliably the steel temperatures during the fire is one reason for the successful prediction of the coupled mechanical behaviour. As already stated the temperatures of the steel studs were well predicted. The fire safety behaviour of partition walls which include door systems is currently being investigated [25]. 


\section{Conclusions}

The full scale fire tests on the steel-stud gypsum-faced partition wall systems provided detailed thermal profiling throughout the wall. Measurements of the displacements caused by the thermal bowing during the duration of the fire were recorded. The experimental data were used to verify a proposed numerical procedure to be used in predicting the thermo-mechanical behaviour of such walls. The following statement can be made:

- The numerical prediction of the thermal behaviour included temperature-dependent thermal properties of the constituent materials in a Finite Element heat transfer model taking into account conduction and convection. The energy consumption in the dehydration of gypsum was accounted for according to published data.

- The sequentially coupled thermo-mechanical model was idealised and simplified based on extensive observations during the construction, fire testing and post-fire examinations of the walls. The non-linear behaviour of the steel studs including material and geometric non-linearity were included in the mechanical model.

- The gypsum boards contribute little to the out of plane stiffness during fire exposure but provide restraint in the plane of the wall for the steel studs. The manufacturing and installation of such partition walls give the steel studs a considerable degree of freedom in the vertical direction with hardly any fixity at the top and the bottom of the wall. This was verified experimentally and incorporated into the mechanical model.

- Comparison between the measured temperatures across the wall and the predicted values showed acceptable agreement until severe events took place such as falling off of the gypsum boards. In particular, the steel studs' temperatures, as presented by thermocouple $\mathrm{T} 27$, were predicted to a good degree of accuracy until such events took place.

- Observations of the method of construction, the events during full-scale fire testing and detailed post-fire examination of such systems were crucial for successful efforts in capturing the fire behaviour in numerical models. The sequentially coupled thermo-mechanical analysis according to the proposed procedure was found to provide an acceptable prediction of the displacement 
behaviour of the wall throughout the fire duration until severe events such as the falling off of the gypsum boards.

- The proposed procedure is based on a thermal analysis carried out on all constituents of the wall assembly. However, the mechanical analysis to determine the thermal bowing was carried out on the steel studs with appropriate representation of the gypsum boards as mechanical boundary conditions.

\section{Acknowledgement}

The support from the Swiss Federal Laboratory for Material Testing and Research (Empa) where the fullscale fire testing took place is hereby gratefully acknowledged. The contributions from the technical and research staff at Empa are gratefully acknowledged.

\section{References}

[1] Hansford, M. (2009). Camberwell fire: lessons must be learned, says government. New Civil Engineer, (7 July 2009).

[2] BS EN1363-1. (1999). Fire resistance tests- Part1: General requirements.

[3] Alfawakhiri, F., Sultan, M. A., and MacKinnon, D. H. (1999). Fire Resistance of Loadbearing Steel-Stud Wall Protected with Gypsum Board: A Review. Fire technology, 35(4), 308-335. Retrieved from http://dx.doi.org/10.1023/A:1015401029995

[4] Sultan, M. (1996). A model for Predicting Heat Transfer Through Noninsulated Steel-Stud Gypsum Board Wall assemblies Exposed to Fire. Fire Technology, Third Quarter 1996.

[5] Sultan, M.A. and Kodur, V.R., (2000). Light-weight frame wall assemblies: Parameters for consideration in fire resistance performance based design. Fire Technology, 36(2), 75-88. 
[6] Feng, M., Wang, Y. C., and Davis, J. (2003). Thermal performance of cold-formed thin-walled steel panel systems in fire. Fire Safety Journal, 38(4), 365-394. doi:10.1016/S0379-7112(02)00090-5

[7] Feng, M. and Wang, Y.C., (2005a). An experimental study of loaded full-scale cold-formed thin-walled steel structural panels under fire conditions. Fire Safety Journal, 40(1), 43-63.

[8] Feng, M. and Wang, Y.C. (2005b). An analysis of the structural behaviour of axially loaded full-scale coldformed thin-walled steel structural panels tested under fire conditions. Thin-walled structures, 43(2), 291332.

[9] Mahendran, M. and Ranawaka, T. (2007). Structural performance of light gauge steel compression members at elevated temperatures, J.Y. LIEW and Y.S. CHOO, eds. In: Proceedings 5th international conference of advances in steel structures, 5-7 December 2007, Singapore, 763-768.

[10] Chen, J. and Young, B., (2007). Experimental investigation of cold-formed steel material at elevated temperatures. Thin-walled structures, 45(1), 96-110.

[11] Ghazi Wakili, K., Hugi, E., Wullschleger, L., and Frank, T. (2007). Gypsum Board in Fire -- Modeling and Experimental Validation. Journal of Fire Sciences, 25(3), 267-282. doi:10.1177/0734904107072883

[12] Bénichou, N.and Sultan, M.A. (2004) "Fire resistance behaviour of lightweight-framed construction" Structures in Fire, Proceedings of the 3rd International Workshop,Ottawa, Ontario, May 10-11, 2004, p. $119-136$

[13] Manzello, S. L., Grosshandler, W. L., and Mizukami, T. (2009). Furnace Testing of Full-Scale Gypsum Steel Stud Non-Load-Bearing Wall Assemblies: Results of Multi-Laboratory Testing in Canada, Japan, and USA. Fire Technology, 46(1), 183-200. doi:10.1007/s10694-009-0090-z

[14] Mehaffey, J. R., Cuerrier, P., and Carisse, G. (1994). A Model for Predicting Heat Transfer Through Gypsum Board/Wood-Stud Walls Exposed to Fire. Fire and Materials, 18, 297-305. 
[15] Young, S., and Clancy, P. (2001). Structural modelling of light-timber framed walls in fire. Fire Safety Journal, 36(3), 241-268. doi:10.1016/S0379-7112(00)00053-9

[16] BS EN1991-1-2. (2009). Eurocode 1: Actions on structures- Part1-2: General actions-Actions on structures exposed to fire.

[17] Ang, C., and Wang, Y. (2009). Effect of moisture transfer on specific heat of gypsum plasterboard at high temperatures. Construction and Building Materials, 23(2), 675-686. Elsevier Ltd. doi:10.1016/j.conbuildmat.2008.02.016

[18] BS EN1993-1-2. (2009). Eurocode 3: Design of steel structures -Part1-2: General rules-Structural fire design.

[19] Clancy, P. (2002). “Advances in Modelling Heat Transfer Through Wood Framed Walls in Fire”. Fire and Materials. Volume 25, 241-254.

[20] Thomas, G. (2002). Thermal Properties of Gypsum Plasterboard at High Temperatures. Fire and Materials, $45,37-45$.

[21] Hopkin, D. J., El-Rimawi, J., Silberschmidt, V., and Lennon, T. (2011). An effective thermal property framework for softwood in parametric design fires: Comparison of the Eurocode 5 parametric charring approach and advanced calculation models. Construction and Building Materials, 25(5), 2584-2595. doi:10.1016/j.conbuildmat.2010.12.002

[22] Hopkin, D. J., Lennon, T., El-Rimawi, J., and Silberschmidt, V. (2011). Full-scale natural fire tests on gypsum lined structural insulated panel (SIP) and engineered floor joist assemblies. Fire Safety Journal, 46(8), 528-542. doi:10.1016/j.firesaf.2011.07.009 
[23] Lennon, T., Hopkin, D., El-Rimawi, J., and Silberschmidt, V. (2010). Large scale natural fire tests on protected engineered timber floor systems. Fire Safety Journal, 45(3), 168-182. doi:10.1016/j.firesaf.2010.02.006.

[24] JRC and CEN (2010). Fire safety in timber buildings, Technical guidance for Europe. SP Report 2010:19. . TC250/SC5

[25] Nassif A. Y. (2012) " Thermal modelling and full-scale fire testing of a steel door-leaf opening into a standard fire" Research, Development, and Practice in Structural Engineering and Construction Vimonsatit, V., Singh, A., Yazdani, S. (eds.), proceedings of ASEA-SEC-1, Perth, November 28Decmber 2, 2012

[26] Bažant, P., Asce, H. M., Le, J., Greening, F. R., \& Benson, D. B. (2008). What Did and Did Not Cause Collapse of World Trade Center Twin Towers in New York ?, (October), 892-907.

[27] BS EN1993-1-2. (2006). Eurocode 3: Design of steel structures —Part1-3: General rules- Supplementary rules for cold formed members and sheeting. 